\title{
Survey of neurohospitalists: subspecialty definition and practice characteristics
}

\author{
David Likosky ${ }^{*}$, Scott Shulman ${ }^{2}$, Lucas Restrepo ${ }^{3}$ and William D. Freeman ${ }^{4}$ \\ 1 Evergreen Hospital Medical Center, Kirkland, WA, USA \\ 2 Maine General Health Systems, Waterville, ME, USA \\ ${ }^{3}$ University of California Los Angeles, Stroke Center, Los Angeles, CA, USA \\ ${ }^{4}$ Neurohospitalist Division, Neurocritical Care Division, Mayo Clinic Florida, Jacksonville, FL, USA
}

Edited by:

S. Andrew Josephson, University of California, USA

\section{Reviewed by:}

Kevin N. Sheth, University of Maryland

School of Medicine, USA

Roy Alcalay, Columbia University, USA

*Correspondence:

David Likosky, Evergreen Hospital Medical Center, 12040 NE 128th St, MS 105, Kirkland, WA 98034, USA. e-mail: dalikosky@

evergreenhealthcare org
Neurohospitalists represent an emerging neurological subspecialty focusing on inpatient neurological disease. Little data exists regarding neurohospitalist practice information and clinical activity. A survey among neurohospitalists was performed to help define the subspecialty, yield demographic information, practice characteristics, and understand clinical and non-clinical activities. During the formation the Neurohospitalist Section of the American Academy of Neurology September 2008, an online survey (29 questions mixed categorical, numerical, and free text) of 93 neurohospitalists was performed. The survey closed on October 13, 2008. The survey achieved a $54 \%$ response rate. Eighty-two percent of respondents were male, mean age 42 (range, 34-68), median practice duration 6 years, with broad distribution of practices across the US. Seventy-five percent of respondents reported having general neurology residency plus additional fellowship training (54\% vascular neurology fellowship, 13\% neurocritical care, and $33 \%$ other no response). Fifty-one percent of neurohospitalists were hired by non-academic (private) institutions, whereas academic institutions hired $49 \%$. There was a wide array of responses for call frequency, duration, number of practice partners, and annual income. A uniform definition of the neurohospitalist subspecialty emerged as one who cares for inpatients, focusing primarily on in-hospital responsibilities. Neurohospitalists defined themselves as inpatient neurological subspecialists. Neurohospitalists have a broad US geographic distribution (and possibly international), in both academic and private practice (or hybrid) forms, and typically provide inpatient and Emergency Department (ED) call coverage for hospitals or outpatient neurologic practices. Most neurohospitalists were involved in administrative aspects of stroke or inpatient quality initiatives.

Keywords: neurohospitalist, neurology hospitalist, hospitalist, subspecialist, hospital practice

\section{INTRODUCTION}

Neurohospitalists are rapidly increasing in numbers in response to pressures to provide timely, cost-effective, and high-quality inpatient neurological care (Avitzur, 2005; Freeman et al., 2008; Josephson et al., 2008). Neurologists are finding it difficult to simultaneously care for inpatients and outpatients. Many neurologists are ceasing Emergency Department (ED) call coverage due to burnout, decreasing reimbursement (versus outpatients), rising litigation risk and malpractice premiums (Institute of Medicine, 2007; Likosky et al., 2009) As a result, neurohospitalists have emerged as "site-specific specialists" focusing on inpatients with neurologic disease that can provide more timely evaluation of ED and hospitalized patients. Beyond direct clinical care, neurohospitalists may focus on inpatient quality metrics, systems-based practice and practice-based improvement. Little is known about this group of neurologists as the growth of this field has been widespread and reactive to local as well as national pressures and needs. The survey was performed in order to understand the nature of this response to the current healthcare environment and aid in identifying any gaps in train- ing that may exist. Given the limited data about this subspecialty (Avitzur, 2005; Freeman et al., 2008; Josephson et al., 2008), we surveyed available neurohospitalists to define and characterize their practice.

\section{MATERIALS AND METHODS}

The authors developed a survey of 29 questions of mixed categorical, numerical and free text data entry in August 2008, focusing on three primary areas: (1) demographics, (2) practice characteristics, and (3) clinical and non-clinical activities (Table 1). At the time of the survey, there was no Neurohospitalist-specific organization. Participants were identified largely through the American Academy of Neurology (AAN) Stroke Section and during a grass roots formation of the AAN Neurohospitalist section from late 2008 to spring 2009 , as well as a small number of known neurohospitalist contacts. Ninty-three neurohospitalists were identified and emailed to participate in an online survey in September 2008. Data collection ended 1 month after survey initiation, and was collected online through Zoomerang. The data are descriptive given the nature of the survey. 
Table 1 | Twenty-nine question neurohospitalist survey.

Question 1: What is your age (numerical response)

Question 2: What is your gender (Male or Female-categorical response)

Question 3: Years since finishing fellowship or residency? (numerical response)

Question 4: Number of years as a neurohospitalists? (numerical response)

Question 5: Are hospitalized patients your primary professional focus? (Yes or no response)

Question 6: Type of neurology fellowship/additional specialty? (categorical and free text)

Question 7: Geographical location of practice (Free text)

Question 8: Type of practice (ordinal response)?

Question 9: Employment model (categorical)

Question 10: How many hospitals do you regularly care for patients? (categorical)

Question 11: How many neurologists are in your practice (numerical)?

Question 12: What is your average yearly income (numerical)?

Question 13: Your salary is best described as base, production, or mixed? (categorical)

Question 14: Are you reimbursed for taking call? (Yes, no, text-entry)

Question 15: What percent time is spent on non-clinical work (numerical)

Question 16: Do you receive additional compensation for administrative/non-clinical work? (Yes, no, categorical)

Question 17: What percentage of your time is spent as a neurohospitalist? (numerical)

Question 18: What percentage of your time is spent on seeing outpatients? (numerical)

Question 19: Number of professional partners involved in inpatient neurology (categorical)?

Question 20: Do non-neurohospitalists share call responsibilities? (categorical)

Question 21: What is the typical duration of call shift as neurohospitalist? (categorical, free text)

Question 22: Rank disorders most frequently encountered as neurohospitalist? (Categorical)

Question 23: The average number of primary inpatients seen each day (you are the attending of record)? (numerical)

Question 24: Average number of new admissions each day? (numerical)

Question 25: Average number of inpatient consultations each day? (numerical)

Question 26: Of these (\#25), how many are new consultations on average? (numerical)

Question 27: Do you work with internal medicine hospitalists regularly? (categorical)

Question 28: What percentage of your practice is adult/pediatric? (numerical)

Question 29: How would you best define "Neurohospitalist?" (free text response)

\section{RESULTS}

A 54\% (52 responses) response rate was achieved. Data was analyzed and summarized in descriptive format and tables with distribution of responses (Table 2). No prior neurohospitalist survey was available for statistical comparison.

\section{DEMOGRAPHICS}

Eighty-two percent of respondents were male with a mean age of 42 (range, 34-68; Table 2). The median practice duration was 6 years (range 0-20). Neurohospitalists practiced throughout the United
Table 2 | Survey results.

\begin{tabular}{|c|c|c|c|c|}
\hline & Max. & Min. & Average & $\begin{array}{l}\text { Standard } \\
\text { deviation }\end{array}$ \\
\hline Age (years) & 68 & 34 & 47.7 & 9.3 \\
\hline Years post residency & 34 & 1 & 13.9 & 10.1 \\
\hline Years as a neurohospitalist* & 28 & 0 & 6.0 & 5.4 \\
\hline Neurologists in co-practice* & 180 & 1 & 16.6 & 32.2 \\
\hline Average yearly income & $\$ 450,000$ & $\$ 120,000$ & $\$ 228,000$ & $\$ 66,119$ \\
\hline \multicolumn{5}{|l|}{ PERCENT OF TIME } \\
\hline Non-clinical work* & 85 & 0 & 18.9 & 15.4 \\
\hline Neurohospitalist* & 100 & 0 & 54.8 & 30.1 \\
\hline Outpatient care* & 90 & 0 & 24.4 & 26.1 \\
\hline Adult cases* & 100 & 97 & 76.6 & 40.5 \\
\hline Pediatric cases* & 20 & 0 & 2.7 & 4.3 \\
\hline \multicolumn{5}{|l|}{ AVERAGE } \\
\hline $\begin{array}{l}\text { Number of inpatients } \\
\text { seen daily* }\end{array}$ & 30 & 0 & 9.6 & 7.3 \\
\hline New admissions* & 10 & 0 & 2.7 & 2.0 \\
\hline Inpatient consult* & 30 & 2 & 7.2 & 5.8 \\
\hline New consult* & 10 & 1 & 3.5 & 2.2 \\
\hline
\end{tabular}

*Adjusted to fit approximations.

States (13 Southwestern, 12 South/Southeastern, 12 Northeastern, 10 Midwest/Southcentral), 2 international (1 Hong Kong and 1 from Greece). One-quarter of respondents reported no formal fellowship training. Three-quarters $(75 \%)$ reported fellowships, $62 \%$ in vascular neurology, $13 \%$ neurocritical care, $13 \%$ other, and remainder unspecified.

\section{PRACTICE CHARACTERISTICS}

Seventy-three percent of respondents reported hospitalized patients as their primary professional focus, while $27 \%$ reported this was not their primary professional focus. Fifty-one percent of neurohospitalists practice in non-academic institutions, whereas $49 \%$ of neurohospitalists practice in an academic institution. The majority (37/52 or $71 \%$ ) practiced at one hospital. Call responsibilities varied widely. Annual income reported varied widely from $\$ 150,000$ to $\$ 450,000$. Eighteen percent $(9 / 50)$ reported a production-based salary, 41/52 (82\%) reported earning base salary with $(36 \%)$ or without $(46 \%)$ incentives, and $4 \%(2 / 50)$ did not report their income. The most common reported base salary $(16 / 39,66 \%)$ was between $\$ 200,000$ and $\$ 250,000$. The number of partners involved in the neurohospitalist practice varied widely: 0 (18\%), 1 (22\%), $2(14 \%), 3(12 \%), 4(6 \%)$, and more than 5 $(28 \%)$. Sixty-nine percent $(34 / 49)$ of respondents reported no additional compensation for taking call, while $6 \%(3 / 49)$ received protected time off in return for call, and 24\% (12/49) reported some other form of financial reimbursement. Thirty-three percent (17) covered inpatient call (ED and inpatient consults) within the neurohospitalist group (i.e., all days, nights and weekends), 33\% (17) shared call with non-neurohospitalist neurologists during nights and weekends only, and 33\% (17) shared all shifts within the entire neurology practice. Call shift duration varied from $8 \mathrm{~h}$ ("day" or "night" call) to 2 weeks, most commonly 24/7 call for 7 days at a time. 


\section{CLINICAL AND NON-CLINICAL ACTIVITIES}

The majority of neurohospitalist care was delivered to adult inpatients (98\%; Table 2). For neurohospitalists admitting as attending, a median of 10 primary patients was seen daily (range, 1-30). Including consults, the daily median was 14 (range, 4-42). Among the top three diagnoses, stroke was most common (49\%), followed by encephalopathy (33\%) and seizure (3\%). On average, $20 \%$ (range 2-85\%) of work hours were devoted to non-clinical duties (e.g., stroke program administration). When asked, 'How you best define "neurohospitalist?" essentially all described a specialist who cares for inpatients, focusing primarily on in-hospital responsibilities.

\section{DISCUSSION}

Neurohospitalist medicine is a site-specific neurologic subspecialty which has rapidly developed a national presence. Sixtyseven percent of neurohospitalists surveyed had fellowship training in either vascular neurology or neurocritical care, which may be a selection bias due to identification of the majority of participants through the AAN stroke section. However, this may reflect the true background and interests of neurohospitalists. Also, it was difficult to quantify the true number of practicing neurohospitalists to know if our sample was truly small. The mean age of respondents was 42 (range, 34-68), 7 years younger than a 1997 survey of general neurologists (Holloway et al., 1999).Our findings generally mirror earlier internal medicine hospitalist surveys which found a younger age compared to outpatient counterparts (Society of Hospital Medicine, http://www. hospitalmedicine.org/).This may be due to the recent emergence of the field, a younger group of physicians, or a survey selection bias.

Other limitations include the relatively low response rate and the population surveyed. However, at the time there was no "neurohospitalist organization" to poll. In essence our survey was obtained from those within AAN members that defined themselves as neurohospitalists, and consistent with the published definition (Freeman et al., 2008). Second, our survey population was small, which made statistical analysis of the data difficult due to lack of prior data and a small overall population. However, we feel it is useful as a comparison for future, larger studies on neurohospitalists.

A number of important data emerged from the survey. First, a consistent definition emerged that neurohospitalists are primarily inpatient neurological subspecialists, with a minimum or absence of outpatient practice. This represents an important step in American medicine similar to that taken by medicine hospitalists more than a decade ago. Neurohospitalists and hospitalists are able to provide more timely care than is possible with a full outpatient schedule. Neurohospitalists often help protect the

\section{REFERENCES}

Avitzur, O. (2005). Neurohospitalists: a new term for a new breed of neurologist. Neurol. Today 5, 44-45.

Freeman, W. D., Gronseth, G., and Eidelman, B. H. (2008). Invited article: is it time for neurohospitalists? Neurology 70, 1282-1288.
Holloway, R. F., Vickrey, B. G., Keran, C. M., Lesser, E., Iverson, D., Larson, W., and Swarztrauber, K. (1999). US neurologists in the 1990's: trends in practice characteristics. Neurology 52 , 1353-1361.

Institute of Medicine (IOM) (2007). Hospital-Based Emergency Care:

clinical schedule of the outpatient neurologists in those practice models by allowing them to practice with less interruption in care. Neurohospitalists spent a significant amount of clinical time with inpatients (most citing 25-75\%). Neurohospitalists' clinical and non-clinical interests align well with those of the hospital given the current emphasis on "pay-for-performance," call coverage and efficient processes.

In addition, neurohospitalists have teaching roles in both academic (49\%) and private (teaching) hospital (29\%) settings (Naley and Elkind, 2006). This suggests neurohospitalists have an important role in training future physicians - neurological and otherwise. Currently neurohospitalist fellowships are limited (Freeman et al., 2008) but this will likely change as the field is defined more fully.

To our knowledge this is the first survey of neurohospitalists, a field which we feel will continue to grow under the pressure to demonstrate high-quality inpatient care. We anticipate the number of neurohospitalists will continue to grow based on the available literature (Freeman et al., 2008; Josephson et al., 2008), the rapid growth within the AAN Neurohospitalist section within the past year to 286 members (N. Poechmann, personal communication), and job advertisements (Dendrite) (Freeman et al., 2008). Neurohospitalist practice appears to appeal to young neurologists who enjoy the inpatient neurologic experience. Evolving issues include the nature and necessity of neurohospitalist-specific training, particularly in light of the most common diagnoses seen, as well as interaction with internal medicine hospitalists and neurology subspecialists. Not all hospitals or practices have sufficient volumes to justify the costs of hiring neurohospitalists (Freeman et al., 2008), but this survey reports a mean volume of 10 patients per day. The neurohospitalist field is ripe for research on quality, patient outcomes, patient safety, and inpatient neurologic disease.

\section{CONCLUSION}

Neurohospitalists are a diverse group of neurologists focusing on inpatient neurologic disease. While no fellowship training was required to become a neurohospitalist, most surveyed had training in cerebrovascular disease or neurocritical care. Those surveyed were split between academic and private practice, worked largely in the inpatient setting and were relatively recent graduates. Much remains unknown about this expanding group. There are a number of challenges inherent to a hospitalist practice, amongst those are transitions and coordination of care, new models of scheduling and practice, quality of care metrics, and cooperation or competition with non-neurohospitalist practices. A future neurohospitalist survey will re-assess similar data to that gathered, and ideally go beyond this to answer many of these other issues that a new and dynamic field must face.

At the Breaking Point [cited 2007 March 7]. National Academy of Sciences. Available at: http://www. iom.edu/CMS/3809/16107/35007. aspx.

Josephson, S. A., Engstrom, J. W., and Wachter, R. M. (2008). Neurohospitalists: an emerging model for inpatient neurological care. Ann. Neurol. 63, 135-140.

Likosky, D., Freeman, W. D., and Eidelman, M. B. (2009).Correspondence RE: Invited article: is it time for neurohospitalists? Letter 72, 859-860. http://www.neurology.org/cgi/ eletters/70/15/1282 
Naley, M., and Elkind, M. S. (2006). Outpatient training in neurology: history and future challenges. Neurology 66, E1-E6.

Conflicts of Interest Statement: The authors declare that the research was conducted in the absence of any commercial or financial relationships that could be construed as a potential conflict of interest.

Received: 16 April 2010; paper pending published: 21 April 2010; accepted: 19 May 2010; published online: 14 June 2010
Citation: Likosky D, Shulman S, Restrepo $L$ and Freeman WD (2010) Survey of neurohospitalists: subspecialty definition and practice characteristics. Front. Neur. 1:9. doi: 10.3389/fneur.2010.00009

This article was submitted to Frontiers in Neurocritical and Neurohospitalist Care, a specialty of Frontiers in Neurology.
Copyright (0) 2010 Likosky, Shulman, Restrepo and Freeman. This is an openaccess article subject to an exclusive license agreement between the authors and the Frontiers Research Foundation, which permits unrestricted use, distribution, and reproduction in any medium, provided the original authors and source are credited. 